\title{
The efficacy of cue exposure with response prevention in extinguishing drug and alcohol cue reactivity
}

Citation for published version (APA):

Havermans, R. C., Mulkens, S., Nederkoorn, C., \& Jansen, A. T. M. (2007). The efficacy of cue exposure with response prevention in extinguishing drug and alcohol cue reactivity. Behavioral Interventions, 22, 121-135. https://doi.org/10.1002/bin.219

Document status and date:

Published: 01/01/2007

DOI:

10.1002/bin.219

Document Version:

Publisher's PDF, also known as Version of record

\section{Document license:}

Taverne

\section{Please check the document version of this publication:}

- A submitted manuscript is the version of the article upon submission and before peer-review. There can be important differences between the submitted version and the official published version of record.

People interested in the research are advised to contact the author for the final version of the publication, or visit the DOI to the publisher's website.

- The final author version and the galley proof are versions of the publication after peer review.

- The final published version features the final layout of the paper including the volume, issue and page numbers.

Link to publication

\footnotetext{
General rights rights.

- You may freely distribute the URL identifying the publication in the public portal. please follow below link for the End User Agreement:

www.umlib.nl/taverne-license

Take down policy

If you believe that this document breaches copyright please contact us at:

repository@maastrichtuniversity.nl

providing details and we will investigate your claim.
}

Copyright and moral rights for the publications made accessible in the public portal are retained by the authors and/or other copyright owners and it is a condition of accessing publications that users recognise and abide by the legal requirements associated with these

- Users may download and print one copy of any publication from the public portal for the purpose of private study or research.

- You may not further distribute the material or use it for any profit-making activity or commercial gain

If the publication is distributed under the terms of Article 25fa of the Dutch Copyright Act, indicated by the "Taverne" license above, 


\title{
THE EFFICACY OF CUE EXPOSURE WITH RESPONSE PREVENTION IN EXTINGUISHING DRUG AND ALCOHOL CUE REACTIVITY
}

\author{
Remco C. Havermans*, Sandra Mulkens, Chantal Nederkoorn \\ and Anita Jansen
}

Maastricht University, Maastricht, The Netherlands

\begin{abstract}
It has been suggested that drug cue-elicited urges and psychophysiological reactions are the results of Pavlovian conditioning processes and that it should be possible to extinguish these responses with cue exposure with response prevention. It has already been shown that subjective cue-elicited urges can be extinguished, but it is unclear whether this is also true for cue-elicited psychophysiological arousal. This was tested in the present study in a heterogeneous sample of drug and alcohol dependent patients. It was found that cue-elicited urges can indeed be extinguished. However, such a clear pattern of extinguished cue reactivity was not found for the psychophysiological measures. Furthermore, the extinction of drug urges was not specific for cue exposure treatment. It is concluded that cue-elicited psychophysiological arousal does not underlie subjective cue reactivity and may not reflect Pavlovian conditioned drug responding. Copyright (C) 2006 John Wiley \& Sons, Ltd.
\end{abstract}

Associative learning has frequently been suggested to underlie the development and maintenance of addictive behavior. Pavlovian learning models of addiction have received considerable research interest in the past 25 years. One of the most prominent of these theories is the compensatory response model by Siegel (1983). According to Siegel, drug consumption disrupts homeostatic functioning. As one learns that certain drug-related cues predict drug intake, one learns to anticipate the drug effect. Drug cues are thus thought to function as conditioned stimuli being associated with drug use. Conditioned drug responding as a result of this association is termed cue reactivity and according to Siegel should comprise psychophysiological responding opposite to the effect of the drug, thus limiting the disruptive effect of drug use on homeostatic functioning. As such a reactivity in most cases will resemble an aversive withdrawal state, this reactivity will be experienced subjectively, as urges to

\footnotetext{
*Correspondence to: Remco C. Havermans, Mastricht University, Faculty of Psychology, Experimental Psychology, P.O. Box 616, 6200 MD Maastricht, The Netherlands. E-mail: r.havermans@psychology.unimaas.nl
} 
use drugs in order to alleviate this aversive state. Although several studies support the notion that drug cue reactivity is opposite to the effect of the drug in question (see e.g., Siegel \& Ramos, 2002), this is not always necessarily so. Therefore, Stewart, de Wit, and Eikelboom (1984) proposed that the primary cue-elicited drug response is isodirectional to the effect of the drug. Through Pavlovian conditioning then, drug cues are thought to be endowed with the ability to directly increase incentive motivation for drug use. In 1999, Carter and Tiffany presented a meta-analysis systematically reviewing most studies concerning the measurement of psychophysiological cue reactivity and came to the conclusion that generally there is more support for the conditioned incentive motivation view. However, they also proposed an alternative explanation for the pattern of psychophysiological reactivity typically found in substance dependent patients. They noted that across different types of drugs the pattern of psychophysiological reactivity is very similar. This finding does not confer with the associative models of addiction that explicitly predict that psychophysiological cue reactivity should be drug-specific; that is, being either isodirectional or opposite to the effects of the given drug. Carter and Tiffany thus state that cue exposure leads to a general arousal response characterized particularly by an increase in skin conductance level and heart rate.

Exposure to drug cues is undoubtedly stressful for substance dependent patients as cue exposure will lead to an increase in drug craving despite the motivation to remain abstinent. When one is exposed to such a stressor, this leads to the release of catecholamines (epinephrine and norepinephrine) that increase blood pressure, heart rate, skin conductance level, and induce peripheral vasoconstriction (Grunberg \& Singer, 1990). Carter and Tiffany (1999) suggest that this arousal response to drug cues can be explained in terms of the nonassociative model of drug use and drug urges proposed by Tiffany (1990). According to Tiffany, drug cues activate a drug action schema allowing for the automatic use of drugs. Impeding automatic drug use leads to frustration and accompanying activation of higher-order cognitive processes to ensure drug consumption. Exposure to cues thus leads to increased arousal, which is reflected by a subjectively experienced urge and psychophysiological reactivity. Although a general arousal response is not predicted by any of the existing associative models of drug addiction, this does not necessarily imply that such a response pattern cannot be the result of Pavlovian conditioning processes. Wise and Bozarth (1987) argue that the primary effect of all drugs of abuse is their psychomotor stimulating, or arousing effect. It is conceivable that drug cues are associated with this arousing effect and hence come to elicit conditioned arousal responding that contributes to the experience of drug urges. Indeed, autonomic arousal can be subject to conditioning (Johnson \& Anderson, 1990). For example, Dawson and Biferno (1973) demonstrated that participants could learn to discriminate between a neutral tone A paired with an electric shock and another neutral tone B that was not paired with the administration 
of the shock, such that presentation of tone A alone came to elicit an increase in skin conductance level and skin conductance responding.

It has been argued that if psychophysiological cue reactivity is indeed a conditioned response contributing to the experience of drug urges, it should be possible to extinguish such responding by applying cue exposure with response prevention (CERP). CERP refers to the treatment in which the patient is repeatedly exposed to cues related to his/her addictive behavior without being able to submit to this behavior. This procedure elicits strong urges, but with repeated exposure the cues lose their predictive value, and hence craving gradually extinguishes (Rankin, Hodgson, \& Stockwell, 1983). Although it is clear that CERP can lead to the successful extinction of subjective cue reactivity (i.e., craving), it has remained unclear to what degree CERP affects psychophysiological cue reactivity as very few CERP studies have incorporated such psychophysiological measures (see also Carter \& Tiffany, 1999) and the few studies that did incorporate psychophysiological measures have rendered equivocal results (see e.g., Drummond \& Glautier, 1994; O’Brien, Childress, McClellan, \& Ehrman, 1990). In the present study, it was hypothesized that cue exposure can lead to the successful extinction of both cue-elicited urges and psychophysiological arousal. This hypothesis was tested in a heterogeneous sample of different drug or alcohol-dependent patients.

\section{METHOD}

\section{Patients}

The study was approved by a medical research ethics committee. All patients in the present investigation signed informed consent prior to their participation in the study.

Patients were recruited from a substance abuse treatment facility in Heerlen, the Netherlands. Patients at this treatment center have a length of stay varying from 14 to 270 days. Upon admission patients are diagnosed by treatment staff (under supervision of the resident psychiatrist) as being either alcohol or drug dependent according to DSM-IV criteria using a structured interview based on the Addiction Severity Index (ASI; McLellan et al., 1985) assessing drug or alcohol use (e.g., frequency, duration, and the experience of tolerance and withdrawal), number of drug-related social problems (e.g., problems with employment, dropping out from school, legal and/or financial problems, and potentially disturbed family relations), history of previous admissions for drug dependence treatment (including the assessment of the patient's psychiatric and medical history), and the patient's personal motivation for seeking treatment. In case of a history and/or current presence of psychiatric comorbidity (i.e., psychotic symptoms, suicidal ideation, or PTSD), the 
patient is always referred to another specialized psychiatric treatment unit. These patients were thus excluded from the present study.

A total of 70 drug or alcohol dependent patients ( 57 men and 13 women, $M$ age $=$ 37 years) agreed to take part in the present study, comprising 36 alcohol dependent patients, 15 cocaine dependent patients, 11 opiate dependent patients, 2 psychostimulant dependent patients, 4 cannabis dependent patients, and 2 benzodiazepine dependent patients. Patients were eligible for participation in the present study if they were at least 18 years old, detoxified and did not take any urge-inhibiting medication (e.g., naltrexone, accamprosate, or benzodiazepines).

\section{Treatments}

Patients were randomly assigned to one of two treatments: Relaxation training (RT: the control treatment), or CERP. The RT group contained 34 patients ( $M$ age $=36$; $M$ number of years of drug abuse prior to treatment $=13.6 ; M$ number of previously received treatments for drug or alcohol dependence $=1.5)$, and the CERP group thus contained 36 patients $(M$ age $=38 ; M$ number of years of drug abuse prior to treatment $=14.2 ; M$ number of received treatments previously for drug or alcohol dependence $=1.6$ ). There were no statistically significant differences between the two groups considering age, the number of years of drug or alcohol abuse prior to current treatment, and the number of previously received treatments for drug or alcohol dependence, all $t \mathrm{~s}<1$.

Each treatment consisted of eleven 1-h sessions in which the patients received either RT or CERP. Rohsenow, Monti and Abrams (1995) have argued that approximately $6 \mathrm{~h}$ of cue exposure should suffice in extinguishing cue reactivity. All sessions took place during weekdays spaced across a period of 4 to 5 consecutive weeks. Both treatments were added to the standard treatment program of the substance abuse treatment facility.

The standard treatment program at this facility includes group therapy, individual counselling, coping skills training, social skills training, aftercare planning and creativity therapy. Patients start each week with an evaluation of the previous week and planning the upcoming week. During each week in treatment, patients receive approximately $8 \mathrm{~h}$ of individual counselling, $2 \mathrm{~h}$ of social skills training, $3 \mathrm{~h}$ of creativity therapy, $1 \mathrm{~h}$ of physical exercise and $8 \mathrm{~h}$ of group therapy that mainly comprises the discussion of coping skills regarding how to cope with high risk situations (i.e., situations in which one is likely to lapse). This latter treatment component is based on Marlatt and Gordon's relapse prevention program (Marlatt \& Gordon, 1985). The remaining time is reserved for personal hygiene, cooking, cleaning, and aftercare planning which comprises personalized aid with finding decent housing and employment (after treatment). 
Treatment providers with at least a Master's degree in Mental Health or with equivalent work experience administered the two forms of treatment (i.e., RT and CERP). They were recruited among the resident treatment staff. Training manuals, weekly supervision and random listening of tape recorded treatment sessions by one of the investigators ensured treatment integrity. Each treatment provider made a report of every session they conducted. The therapists were trained to be able to provide both types of treatment. This allowed us to randomly assign each patient to one of the available treatment providers to control for a potential therapist by treatment confound. Further, all therapists were blind with respect to the explicit research hypothesis. The therapists were told that the main goal of the study was to test the efficacy of two different treatment components (i.e., RT and CERP) aimed at reducing the probability of a relapse. The therapists were thus unaware that RT served as the control treatment.

\section{Cue Exposure with Response Prevention (CERP)}

Patients were told that the CERP was intended to decrease the urge to drink alcohol or use drugs in situations related to their addictive behavior, hence reducing the probability of a relapse after treatment. The first two sessions consisted of explaining the rationale of the treatment and identifying drug-related cues and triggers. Each of the following nine exposure sessions consisted of: (1) baseline urge rating, (2) active exposure to the drug-related cues, and (3) imaginal exposure.

During the exposure sessions, the urge to drink alcohol or use a specific drug was assessed every 10 min on 100-mm Visual Analogue Scales (VASs) ranging from 0 'no urge at all' to 100 'near irresistible urge,' A schematized representation of the rationale lay visible on the table, in order for the therapist to refer to the rationale when deemed necessary. Following each session, the therapists briefly evaluated the session with their patient.

No homework was provided as to limit the danger of a lapse (and subsequent exclusion from the study) in between sessions and as to limit the probability of leakage. To further limit leakage, all patients were explicitly instructed to discuss treatment experiences individually with a treatment staff member and not with any of their fellow-patients.

\section{Relaxation Training (RT)}

Patients randomly assigned to group RT received a similar amount of individual treatment sessions as the patients receiving CERP, and comprised training in different relaxation techniques. RT is incorporated in many standard treatment programs and its rationale has high credibility, but it has been found to have no long term effect on 
alcohol and drug use outcomes and is not aimed at extinguishing or directly affecting craving (see Drummond \& Glautier, 1994; Klajner, Hartman, \& Sobell, 1984). As this form of treatment is sufficiently different from CERP, it was incorporated in the present study to serve as a control treatment.

Patients were told that RT is intended to reduce the chance of relapse by managing one's experience of negative emotions due to stressful life events. In the first two sessions, patients were taught to identify stressful events and to become aware of their physiological reactions to such events. In the following nine 1-h sessions, they were taught several different relaxation techniques. As for CERP, no homework was provided.

\section{Cue Reactivity Assessment}

Directly before and after treatment (CERP or RT), all patients received a cue reactivity assessment. This comprised the recording of skin conductance level (SCL), skin temperature (STMP), changes in finger pulse amplitude (FPA) thus measuring either peripheral vasoconstriction or vasodilatation (see Nederkoorn, Smulders, Havermans, \& Jansen, 2004), and interbeat interval (IBI) as a measure for heart rate using Psylab 7 measuring devices (Contact Precision Instruments, UK). SCL was measured with two $\mathrm{Ag}-\mathrm{AgCl}$ electrodes, placed on the thenar and hypothenar eminences of the palm of the nondominant hand. STMP was measured with a thermistor placed on the back of the nondominant hand. FPA and IBI were determined with the aid of finger pulse photoplethysmography, with the sensor placed on the index finger of the nondominant hand. Next to the measurement of psychophysiological cue reactivity, momentary subjective cue-elicited urge was measured with the 100-mm VASs described above.

The patient was briefly informed about the general procedure of the measurement and was then asked to wash his hands with water. Next, he was connected to the psychophysiological measuring devices and was asked to sit still during the entire assessment. The assessment started with a 2-min baseline recording of psychophysiological reactivity. This baseline measurement was intended to bring the diverse autonomic measures to resting level. After these $2 \mathrm{~min}$, the patient was asked to indicate on a VAS the momentary urge to use a given drug, after which he was given a small bar of soap. He was instructed to focus his attention on the bar of soap for a period of $5 \mathrm{~min}$ (i.e., holding it, and looking and smelling at it), after which he had to indicate his drug or alcohol urge on a VAS again. After exposure to the neutral soap cue, the patient was exposed to personalized drug or alcohol cues for another 5 min. During this cue exposure, the patient was instructed to concentrate on the cues, to look at the cues, handle the cues and to smell at the cues (at least if there was anything to smell). After this drug cue exposure, the patient rated his drug or alcohol urge again. 
One might argue that the unbalanced order of exposure to the neutral cue and the drug cues introduces a methodological confound. However, any urges elicited by exposure to drug cues are not simply diminished with subsequent exposure to a neutral cue. Counterbalancing the order of exposure to a neutral cue and drug cues would thus lead to a severe underestimation of cue reactivity. Therefore, it is generally preferred (and accepted) to assess cue reactivity by exposing the drug dependent participant to a neutral cue followed by exposure to drug cues (see also Havermans, Debaere, Smulders, Wiers, \& Jansen, 2003).

\section{RESULTS}

Of the 70 patients that were initially recruited, 6 patients dropped out before actual participation in the present study. The main reason for this attrition being relapse and receiving subsequent mandatory discharge from the treatment facility. The results are displayed in Table 1, showing mean reactivity when exposed to the neutral cue and the drug-related cues at the cue reactivity assessments before and after treatment for each group.

\section{Cue Reactivity Assessment}

To determine whether the cue exposure procedure as conducted during the cue reactivity assessments indeed induced cue reactivity, one sample $t$-tests were conducted with the contrast between responding to the drug cues and the neutral cue for each cue reactivity measure as the dependent variable. Due to hardware failures, we failed to record data of 3 patients concerning SCL, 2 patients concerning STMP, 2 patients concerning IBI, and 7 patients concerning FPA at the pre-treatment measurement of cue reactivity. As hypothesized, the patients demonstrated psychophysiological cue reactivity indicative of an arousal response. Table 2 shows the mean cue-elicited changes in SCL, STMP, IBI, and FPA as a function of primary drug dependence.

Overall, it was found that when exposed to drug cues, the patients demonstrated a significant increase in SCL, $t(60)=9.18, p<0.001, d=1.18$. As can be inferred from Table 1, the two groups appear to differ with respect to their overall mean SCL at pretreatment testing. This might be a problem as according to the law of initial values an initially high SCL could have limited a potential change in SCL (Wilder, 1967). If so, this would mean that cue reactivity with regard to SCL would be smaller for group RT than for CERP prior to treatment. To test this possibility we conducted an additional 2 (Group) $\times 2$ (Cue: neutral vs. drug cue) analysis of variance (ANOVA). A main effect of Cue was found, $F(1,61)=116.99, p=0.001$, and a main effect of Group, 


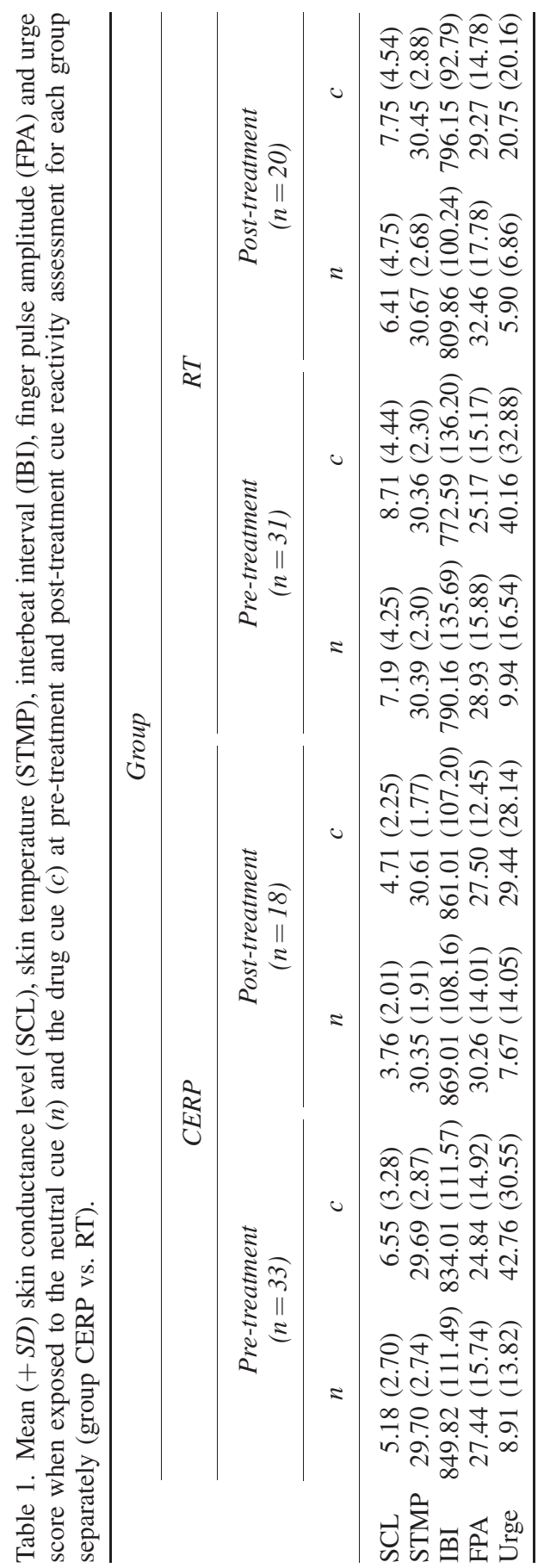


Table 2. Mean cue-elicited psychophysiological reactivity $(+S D)$ at the pre-treatment assessment as a function of primary substance dependence.

\begin{tabular}{lccccr}
\hline \multicolumn{5}{c}{ Primary substance dependence } \\
\cline { 2 - 6 } & $\begin{array}{c}\text { Alcohol } \\
(n=33)\end{array}$ & $\begin{array}{c}\text { Cocaine } \\
(n=15)\end{array}$ & $\begin{array}{c}\text { Opiates } \\
(n=10)\end{array}$ & $\begin{array}{c}\text { Psychostimulants } \\
(n=2)\end{array}$ & $\begin{array}{c}\text { Cannabis } \\
(n=4)\end{array}$ \\
\hline SCL & $1.18(1.13)$ & $1.89(0.94)$ & $1.38(0.92)$ & $1.26(1.04)$ & $2.08(0.48)$ \\
STMP & $-0.05(0.63)$ & $-0.06(0.60)$ & $0.16(0.64)$ & $-0.05(0.49)$ & $0.00(0.28)$ \\
IBI & $-20.95(35.55)$ & $-6.75(36.77)$ & $-13.08(22.56)$ & $-29.00(14.44)$ & $-21.29(35.97)$ \\
FPA & $-2.76(5.86)$ & $-3.46(8.78)$ & $-3.62(4.15)$ & $-14.40(9.74)$ & $1.79(10.16)$ \\
\hline
\end{tabular}

$F(1,61)=5.02, p=0.03$, but no Group $\times$ Cue interaction, $F(1,61)<1, p=0.58$. The absence of a Group $\times$ Cue interaction thus demonstrates that the difference in initial SCL between groups had had no effect on cue-elicited change in SCL. This between groups difference, then, can mainly be attributed to two outliers in-group RT, who demonstrated an abnormally high SCL which was more than $2.5 S D$ above the average SCL of this group. Conducting another 2 (Group) $\times 2$ (Cue: neutral vs. drug cue) ANOVA without these two outliers again revealed a significant main effect of Cue, $F(1,59)=120.11, p<0.001$, but no effect of Group, $F(1,59)=2.71, p=0.11$. Further, no Group $\times$ Cue interaction was found, $F(1,59)=0.50, p=0.48$.

As for the other psychophysiological measures of cue reactivity it was found that the patients demonstrated no change in STMP, $t(61)=0.22, p=0.83, d=0.03$, a significant decrease in IBI that reflects heart rate acceleration, $t(61)=4.40, p<0.001$, $d=0.56$, and a marginally significant decrease in FPA reflecting vasoconstriction, $t(56)=1.73, p=0.09, d=0.23$. These results indicate that the cue exposure procedure was successful at eliciting psychophysiological cue reactivity that indeed appears to reflect a general arousal response as has been argued by Carter and Tiffany (1999). Further, it was found that exposure to the drug cues led to a significant increase in subjectively experienced urge to either drink alcohol or use a particular drug, $t(63)=9.70, p<0.001, d=1.21$. However, unexpectedly this cue-elicited urge responding did not correlate with any of the psychophysiological measures of cue reactivity described above, all $p \mathrm{~s}>0.50$. Pearson bivariate correlation coefficients $(r)$ are displayed in Table 3.

\section{Extinction of Cue Reactivity}

To determine whether exposure led to the successful extinction of cue reactivity, 2 (Time: pre-treatment versus post-treatment) $\times 2$ (Group: CERP vs. RT) repeated measures ANOVAs were conducted for each separate cue reactivity measure, except 
Table 3. Pearson bivariate correlation coefficients $(r)$ between cue-elicited urge and SCL, STMP, IBI, and FPA at the pretreatment cue reactivity assessment.

\begin{tabular}{lr}
\hline & Urge \\
\hline SCL & 0.09 \\
STMP & -0.05 \\
IBI & -0.04 \\
FPA & -0.14 \\
\hline
\end{tabular}

STMP as patients did not demonstrate any cue reactivity for this measure at the pretreatment cue reactivity assessment. Similar to the cue reactivity assessment, the contrast between responding to the drug-related cues and the neutral cue served as the dependent variable.

A total of $40 \%$ of the patients (26 patients) dropped out before the end of the study leaving 18 participants in group CERP (44\% drop-out) and 20 in group RT (34\% drop-out), the main reason for this attrition being, again, a lapse followed by mandatory discharge from the treatment facility. We conducted a Chi-square analysis to test for a potential difference in the level of attrition between groups. It was found that type of treatment had not differentially affected treatment attrition, $\chi^{2}=0.55$, $p=0.46$, and Cramer's $V=0.089$. Insofar one can speak of an association between treatment assignment (CERP vs. RT) and treatment attrition, this association was very weak.

As a high rate of attrition may affect the established equivalence between groups at post-test (see Barker, Pistrang, \& Elliott, 1994), we conducted several $t$-tests to check whether this had happened. The two groups comprising just the completers did not significantly differ in age $[t(36)=0.37]$, the mean number of years of drug abuse prior to treatment $[t(36)=0.05]$, and the mean number of treatments received previously for drug or alcohol dependence $[t(36)=0.26]$.

Only the data from patients who completed the treatment (including post-treatment cue reactivity assessment) were entered into the following analyses. Due to hardware failures we failed to record data from 8 patients concerning SCL, 2 patients concerning IBI, and 9 patients concerning FPA at the post-treatment cue reactivity assessment. The change in cue-elicited changes in SCL, IBI, FPA and urge across cue reactivity assessments (pre-treatment vs. post-treatment) per group (RT vs. CERP) is depicted in Figure 1.

No overall extinction of cue-elicited increase in SCL was found, reflected by the absence of an effect of Time (before vs. after treatment), $F(1,28)<1, \eta^{2}=0.002$, and the absence of an interaction between Time and Group assignment, $F(1,28)<1$, $\eta^{2}=0.001$. Finally, no main effect of Group was found for cue-elicited SCL, $F(1,28)=2.07, p=0.16, \eta^{2}=0.069$. A similar pattern of results was found for 

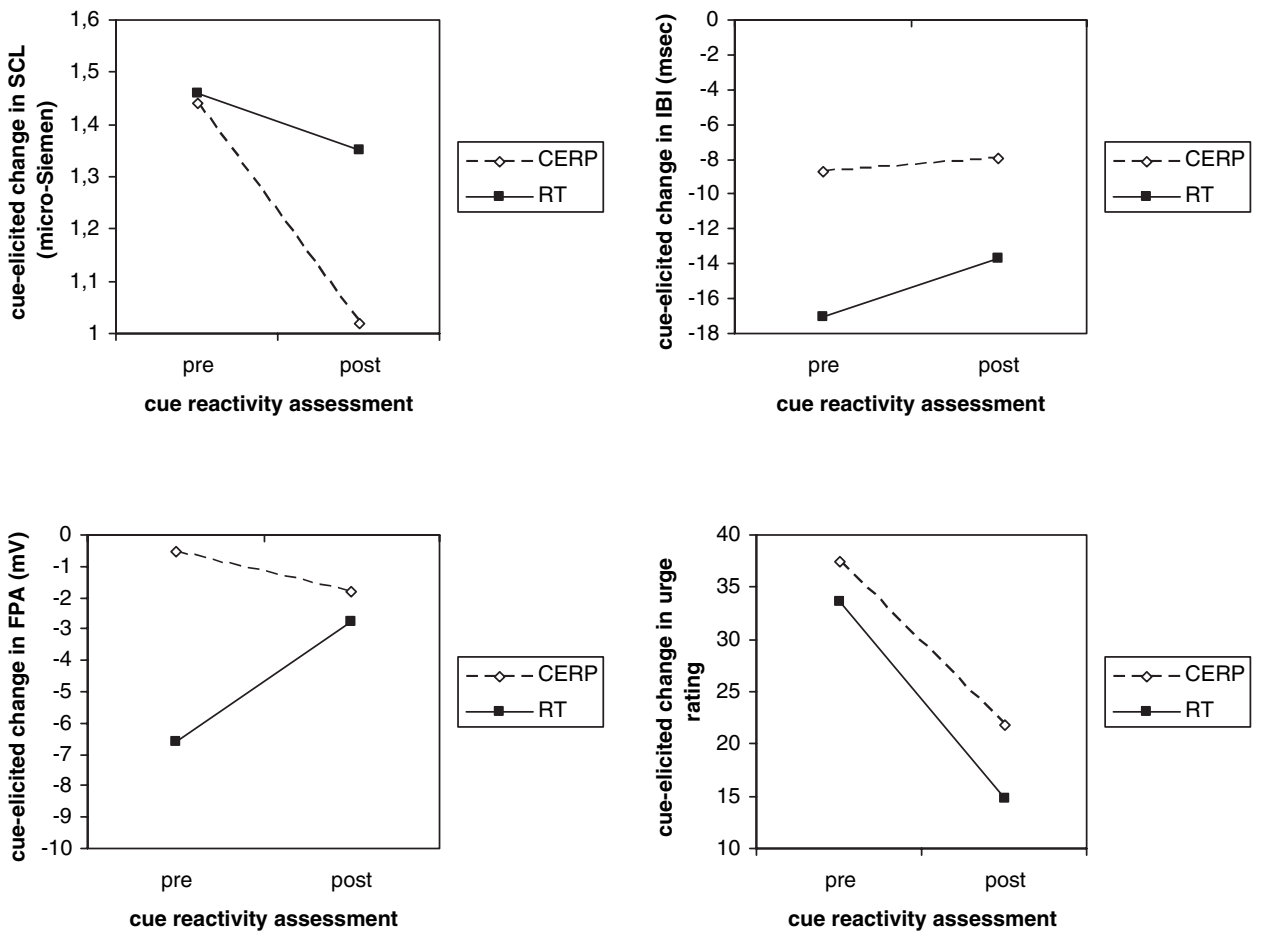

Figure 1. Mean cue-elicited changes of SCL, IBI, FPA, and urge ratings at the pre- and post-treatment cue reactivity assessment for each separate group (CERP vs. RT).

cue-elicited decrease in IBI. Again, no extinction of this measure was found, that is, no main effect of Time $\left(\eta^{2}=0.004\right)$ nor a Time $\times$ Group interaction $\left(\eta^{2}=0.001\right)$ was found, $F s(1,34)<1$. Also, no main effect of Group was found, $F(1,34)=1.06$, $p=0.31, \eta^{2}=0.030$. When examining the cue-elicited decrease in FPA, no effect of Time was found, $F(1,27)=1.38, p=0.25, \eta^{2}=0.041$. However, a Time $\times$ Group interaction was found, $F(1,27)=4.97, p=0.03, \eta^{2}=0.149$. Contrary to our expectations though, this interaction reflects the extinction of cue-elicited vasoconstriction in specifically group RT. This can be attributed to the difference in cue-elicited vasoconstriction between the two groups at the pre-treatment cue reactivity assessment, as can be inferred from Figure 1. No effect of Group was found for FPA, $F(1,27)=1.91, p=0.18, \eta^{2}=0.066$. In contrast to the psychophysiological measures, cue-elicited urge did extinguish, reflected by a main effect of Time, $F(1,36)=10.07, p=0.003, \eta^{2}=0.220$. However, contrary to our expectations, no Time $\times$ Group interaction was found, $F(1,36)<1, \eta^{2}=0.002$. Further, no effect of Group was found for cue-elicited urges, $F(1,36)<1, \eta^{2}=0.026$. 


\section{DISCUSSION}

In the present study, it was investigated whether cue-elicited psychophysiological arousal and drug or alcohol urges can be extinguished. Associative models of addictive behavior predict that cue reactivity (both subjective and psychophysiological reactivity) can be extinguished in a drug dependent patient when this patient is repeatedly exposed to cues associated with his/her alcohol or substance use. No clear support for this associative learning view was found though. Firstly, psychophysiological cue reactivity appears to reflect a general arousal response. This is in contrast with existing associative models of addictive behaviour that predict that cue reactivity should be drug-specific. The present study, however, demonstrates that drug cue-elicited psychophysiological reactions generally comprise an increase in SCL and heart rate, and peripheral vasosconstriction, indicative of an arousal response. Secondly, none of the cue-elicited arousal responses correlated with the degree of cue-elicited urges. As associative models of addictive behavior explicitly state that craving is the subjective interpretation of cue-elicited psychophysiological responding, one would have expected a positive correlation between cue-elicited urges and psychophysiological cue reactivity. Thirdly, psychophysiological cue reactivity did not extinguish at all. The latter result is not a novel finding. For example, O'Brien and colleagues (1990) also failed to extinguish cue-elicited arousal in cocaine dependent patients, even after 15 cue exposure sessions. However, it should be noted that the inability to extinguish cue-elicited psychophysiological arousal does not necessarily imply that such reactivity cannot be regarded as conditioned drug responding as some forms of conditioned responding (e.g., conditioned taste aversion) are extremely resistant to extinction. Furthermore, the observation that psychophysiological cue reactivity reflects general arousal responding can also be attributed to the fact that the measures in the present study are particularly sensitive to arousal. It is possible that other measures are more drug-specific and thus may have yielded a different pattern of results. Of course, considering the relatively small sample size due to treatment attrition one could argue that the present study lacked statistical power to detect a meaningful effect of CERP on psychophysiological cue reactivity. However, considering the extremely small effect sizes for the relevant Group $\times$ Time interactions $\left(\eta^{2}<0.01\right.$; see Cohen, 1977) it is highly unlikely that within the present study CERP had any specific and meaningful effect on psychophysiological cue reactivity. These effect sizes though should be interpreted with some caution considering the heterogeneity of the present study sample. Unfortunately, we could not control for this heterogeneity without seriously limiting statistical power.

Nonetheless, cue-elicited urges did extinguish and thus together with the absence of a positive correlation between cue-elicited urges and psychophysiological 
reactivity the present results demonstrate that cue-elicited arousal responding does not underlie or contribute to cue-elicited craving. Tiffany (1990) explicitly regards cue-elicited arousal and urge responding as independent measures and the present results thus appear to corroborate his view that psychophysiological cue reactivity (i.e., arousal responding) reflects subjectively experienced frustration of not being able to use a given drug or alcohol (see also Carter \& Tiffany, 1999). However, as according to Tiffany's model of addiction an increase in experienced arousal should also give rise to drug urges, this notion too fails to explain the absence of a positive correlation between arousal responding and the subjectively experienced degree of craving. Further, this cognitive model cannot explain the apparent extinction of cueelicited drug and alcohol craving. Although this then suggests that at least subjective cue reactivity reflects conditioned drug responding, an associative model of addiction cannot explain the present extinction of urges in both the group having received CERP and the group having received RT. The latter treatment is not designed to explicitly affect cue-elicited urges, whereas CERP is. This then is a somewhat puzzling result. However, it is not an isolated result. Dawe and colleagues (1993), investigating the efficacy of cue exposure in the treatment of opiate addiction, found that both a group of patients receiving at least six individual cue exposure sessions and a group of patients receiving a control treatment (i.e., group therapy sessions) demonstrated a significant decrease in cue reactivity. As in the present study, these treatments were superimposed on a standard hospital treatment program. Dawe and colleagues argued that this standard treatment may contain elements of cue exposure treatment hence explaining the significant decrease in both groups. This is also true for the standard treatment program that the patients in the present study received at their treatment facility. One element of this program comprised discussing how to cope with high risk drug-related situations. Although this is a much less structured and probably less intense form of exposure than a CERP session, it may have been sufficient for the successful extinction of cue-elicited craving. Of course, the extinction of urge responding in both groups can also be attributed to social desirable responding, that is, patients are unwilling to admit experiencing a strong urge to drink alcohol or to use a particular drug when still in treatment. Although such social desirable responding (or non-responding) cannot be discarded as a viable explanation for the present pattern of results, one then would have expected patients to also not demonstrate a clear pattern of cue-elicited craving at the pre-treatment cue reactivity assessment. Clearly, though, they did. Of course, as both treatments were conducted at the same time in the same treatment facility, some leakage between the two treatment conditions may have occurred leading to the observed extinction of craving in both groups. As noted above, in an attempt to control for such leakage, we repeatedly instructed the participating patients not to share their treatment with their fellow-patients. Further, treatment staff continuously monitored patients' adherence to this instruction. None of the treatment 
providers reported observing any indication of leakage and thus one can conclude that leakage was kept at a minimum and is unlikely to have played an important role.

The apparent survival of cue-elicited arousal as opposed to the decrease in cueelicited craving may be attributed to the fact that although one may very well learn to control drug urges, this still does not mean that one should become indifferent to being exposed to drug-related cues. Cues may obtain an affective value through evaluative conditioning. When a neutral stimulus is paired with a positive or negative cue, some of the valence of the affective stimulus will transfer to the neutral stimulus. In contrast to Pavlovian conditioned responding, this acquired valence is extremely resistant to an extinction procedure (see De Houwer, Thomas, \& Baeyens, 2001). The question is what valence drug-related cues acquire. At face value, one could argue that drug cues should have a positive hedonic value as they refer to the positive rewarding effects of drug consumption. However, drug use also has negative consequences. Indeed, as Robinson and Berridge (2000) have pointed out, many drug dependent patients can experience a strong desire to use a given drug and at the same time report disliking the drug.

The present discussion is admittedly speculative. Further research is thus warranted. Prominent research topics may concern determining the exact nature of cue-elicited arousal responding and the question to what degree such responding predicts frequency of drug consumption or the probability of a relapse.

\section{ACKNOWLEDGEMENTS}

The authors would like to thank Anja Meijboom, Maarten Vanwingh and Rolf Sanderson for the many helpful discussions, for their aid in recruitment and training of the treatment providers, and for their aid in the recruitment of the participants.

\section{REFERENCES}

Barker, C., Pistrang, N., \& Elliott, R. (1994). Research methods in clinical and counseling psychology. Chichester: Wiley.

Carter, B. L., \& Tiffany, S. T. (1999). Meta-analysis of cue reactivity in addiction research. Addiction, 94, 327-340.

Cohen, J. (1977). Statistical power analysis for the behavioral sciences. New York: Academic Press.

Dawe, S., Powell, J., Richards, D., Gossop, M., Marks, I., Strang, J., \& Gray, J. A. (1993). Does postwithdrawal cue exposure improve outcome in opiate addiction? A controlled trial. Addiction, 88, $1233-1245$.

Dawson, M. E., \& Biferno, M. A. (1973). Concurrent measurement of awareness and electrodermal classical conditioning. Journal of Experimental Psychology, 101, 55-62. 
De Houwer, J., Thomas, S., \& Baeyens, F. (2001). Associative learning of likes and dislikes: A review of 25 years of research on human evaluative conditioning. Psychological Bulletin, 127, 853-869.

Drummond, D. C., \& Glautier, S. P. (1994). A controlled trial of cue exposure treatment in alcohol dependence. Journal of Consulting and Clinical Psychology, 62, 809-817.

Grunberg, N. E., \& Singer, J. E. (1990). Biochemical measurement. In J. T. Cacioppo, \& L. G. Tassinary (Eds.), Principles of psychophysiology: Physical, social and inferential elements (pp. 149-176). New York: Cambridge University Press.

Havermans, R. C., Debaere, S., Smulders, F. T. Y., Wiers, R. W., \& Jansen, A. (2003). Effect of cue exposure, urge to smoke, and nicotine deprivation on cognitive performance in smokers. Psychology of Addictive Behaviors, 17, 336-339.

Johnson, A. K., \& Anderson, E. A. (1990). Stress and arousal. In J. T. Cacioppo, \& L. G. Tassinary (Eds.), Principles of psychophysiology: Physical, social and inferential elements (pp. 216-252). New York: Cambridge University Press.

Klajner, F., Hartman, L. M., \& Sobell, M. B. (1984). Treatment of substance abuse by relaxation training: A review of its rationale, efficacy and mechanisms. Addictive Behaviors, 9, 41-55.

Marlatt, G. A., \& Gordon, J. R. (1985). Relapse prevention: Maintenance strategies in the treatment of addictive behaviors. New York: The Guilford Press.

McLellan, A. T., Luborsky, L., Cacciola, J., Griffith, J., Evans, F., Barr, H. L., \& O’Brien, C. P. (1985). New data from the Addiction Severity Index: Reliability and validity in three centers. Journal of Nervous and Mental Disease, 173, 412-423.

Nederkoorn, C., Smulders, F., Havermans, R., \& Jansen, A. (2004). Exposure to binge food in bulimia nervosa: Finger pulse amplitude as a potential measure of urge to eat and predictor of food intake. Appetite, 42, 125-130.

O’Brien, C. P., Childress, A. R., McClellan, T., \& Ehrman, R. (1990). Integrating systematic cue exposure with standard treatment in recovering drug dependent patients. Addictive Behaviors, 15, 355-365.

Rankin, H., Hodgson, R., \& Stockwell, T. (1983). Cue exposure and response prevention with alcoholics: A controlled trial. Behaviour Research and Therapy, 21, 435-446.

Robinson, T. E., \& Berridge, K. C. (2000). The psychology and neurobiology of addiction: An incentivesensitization view. Addiction, 95 (Suppl. 2), 91-117.

Rohsenow, D. J., Monti, P. M., \& Abrams, D. B. (1995). Cue exposure treatment for alcohol dependence. In D. C. Drummond, S. T. Tiffany, S. Glautier, \& B. Remington (Eds.), Addictive behaviour: Cue exposure theory and practice. Chichester: Wiley.

Siegel, S. (1983). Classical conditioning and drug effect. In R. Smart, F. Glaser, Y. Israel, H. Kalant, R. Popham, \& W. Schmidt (Eds.), Research advances in alcohol and drug problems (pp. 207-246). New York: Plenum Press.

Siegel, S., \& Ramos, B. M. C. (2002). Applying laboratory research: Drug anticipation and the treatment of drug addiction. Experimental and Clinical Psychopharmacology, 10, 162-183.

Stewart, J., de Wit, H., \& Eikelboom, R. (1984). Role of unconditioned and conditioned drug effects in the self-administration of opiates and stimulants. Psychological Review, 91, 251-268.

Tiffany, S. T. (1990). A cognitive model of urges and drug-use behaviour: Role of automatic and nonautomatic processes. Psychological Review, 97, 147-168.

Wilder, J. (1967). Stimulus and response: The law of initial value. Bristol: Wright.

Wise, R. A., \& Bozarth, M. A. (1987). A psychomotor stimulant theory of addiction. Psychological Review, 94, 469-492. 